\title{
The Relationship between Serum Levels of Oxidative Stress Biomarkers and Dysmenorrhea, Dyspareunia and Pelvic Pain in Women with
}

\section{Endometriosis}

\author{
Leila Amini ${ }^{1}$, Maryam Shami ${ }^{2}$, Razieh Chegini ${ }^{3}$
}

\begin{abstract}
Background \& Aims: Endometriosis is a common disorder associated with an increased risk of cancers, especially ovarian cancer. One of the most prevalent symptoms of this disease is pelvic pain, which is the major complaint among patients during menstruation. While the pathophysiology of endometriosis and the mechanisms responsible for its complications, namely pelvic pain and infertility, are not yet well understood, it seems that oxidative stress plays an undeniable role in the pathogenesis of endometriosis. In other words, the production of large amounts of inflammatory mediators by endometriosis tissue can explain and be responsible for the onset and exacerbation of pelvic pain. There is an apparent imbalance between oxygen free radicals and antioxidants in the endometrial tissue of diagnosed women. In addition, decreased total antioxidant capacity is observed in the peritoneal fluid in women with endometriosis, which is indicative of inadequate antioxidant status. Even though a significant relationship has been reported between symptoms of pelvic pain and indicators of peritoneal oxidative stress in women with endometriosis in some studies, there are still conflicting theories about the relationship between serum biomarkers of oxidative stress and endometriosis. With this background in mind, the present study aimed to determine the relationship between serum levels of oxidative stress biomarkers and dysmenorrhea, dyspareunia, and pelvic pain in women with endometriosis who referred to Sarem Fertility \& Infertility Research Center in Tehran, Iran in 2017.

Materials \& Methods: This was a descriptive, correlational and cross-sectional study performed on 60 women aged 15-49 years with symptoms of endometriosis. The inclusion criteria were diagnosis of endometriosis based on clinical symptoms and laparoscopy, no current pelvic inflammation disease and adenomyosis, no smoking, or alcohol and drug consumption, no chronic underlying diseases, and no psychological diseases (data were obtained through self-report). Subjects were selected by convenience sampling, and written informed consent was obtained from the participants prior to the study. Data were collected using a demographic characteristics questionnaire, fertility profile questionnaire, endometriosis symptoms checklist, research laboratory information record sheet, and visual analogue scale (VAS) for measuring pain. Following filling out the scales and questionnaires, $10 \mathrm{ccs}$ of the blood sample were taken from each of the volunteers under sterile conditions in citrate tubes and stored after centrifugation at $-20^{\circ} \mathrm{C}$. Afterwards, blood samples were analyzed, and data analysis was carried out in SPSS version 16 using Pearson's correlation coefficient. In addition, a P-value of below 0.05 was considered statistically significant.

Results: The mean age of the participants was 33.16 \pm 5.41 years and the mean age of their spouses was $35.96 \pm$ 8.62. Moreover, the subjects had a body mass index (BMI) of $25.92 \pm 5.94 \mathrm{~kg} / \mathrm{m} 2$, and most of them were housewives $(68.3 \%)$ and had an academic degree (51.7\%). Based on VAS score range of 0-100, the mean score of dysmenorrhea in the subjects was reported to be $50.76 \pm 32.90$, whereas their mean scores of dyspareunia and pelvic pain were $23.70 \pm 25.20$ and $21.05 \pm 23.49$, respectively. Furthermore, most of the participants in the study had no history of previous delivery (83.3\%) and abortion (75\%). Moreover, dysmenorrhea (96.7\%), dyspareunia $(66.6 \%)$ and chronic pelvic pain $(73.3 \%)$ were reported in most participants. The results of this study showed that women participating in this study had ROS values of $5.77 \pm 0.57$ micromoles, TAC of $0.35 \pm 0.12$ micromoles

\footnotetext{
1. Nursing Care Research Center, Department of Midwifery, School of Nursing and Midwifery, Iran University of Medical Sciences, Tehran, Iran

2. Sarem Fertility \& Infertility Research Center, Iran University of Medical Sciences, Tehran, Iran (Corresponding author) Tel: +98214702 Email: m.shami@yahoo.com
}

3. Department of Midwifery, School of Nursing and Midwifery, Iran University of Medical Sciences, Tehran, Iran
\end{abstract}


and MDA of $38.06 \pm 24.9$ micromoles. According to the results, there was a significant relationship between the level of pelvic pain, dysmenorrhea and dyspareunia.

Conclusion: In this study, the majority of the participants suffered from pelvic pain, dysmenorrhea and dyspareunia, which was not unexpected due to the fact that endometriosis is the main factor for these conditions. The high prevalence of these pains has been reported in other studies as well. There is a theory that very small recurrent bleeding in endometriosis lesions and subsequent inflammation may be responsible for menstrual cramps. On the other hand, stretching of the uterosacral ligament, which contains endometriosis tissue, during intercourse, as well as the proximity of nerve fibers to abnormal endometrial tissue, may explain the dyspareunia created in these women. Immune system dysfunction due to endometriosis lesions can be another cause of pelvic pain (e.g., endometriosis), which ultimately leads to neuropathic pains. These patients have also reported pelvic pain caused by tissue degradation induced by immune processes. According to the results, there was no relationship between the severity of dysmenorrhea, dyspareunia, and chronic pelvic pain with the number of reactive oxygen species and the total antioxidant capacity of malondialdehyde in the participants. In a research, Amreen et al. mentioned a significant association between glutathione peroxide levels and dysmenorrhea in women with endometriosis. However, oxidative stress was only slightly exacerbated in the subjects. Moreover, the decrease of antioxidants was insignificant in women with endometriosis and chronic pelvic pain, and even the increase in the concentration of lipid peroxides, which occurs in peritoneal fluid, is not observed in the blood. The results were indicative of no significant relationship between chronic leg pain and dyspareunia with levels of oxidative stress biomarkers. It is generally believed that an increase in oxidative stress of those with dysmenorrhea depends on oxygen-free radicals. However, no studies have clearly mentioned the existence and relationship of oxygen-free radical balance and antioxidant systems with dysmenorrhea. Nonetheless, further studies are required to investigate this issue. It is recommended that oxidative stress biomarkers in peritoneal fluid in women with endometriosis be evaluated in future studies.

Keywords: Endometriosis, Oxidative Stress, Pelvic Pain, Dyspareunia, Dysmenorrhea

\section{Conflict of Interest: No}

How to Cite: Amini L, Shami M, Chegini R. The Relationship between Serum Levels of Oxidative Stress Biomarkers and Dysmenorrhea, Dyspareunia and Pelvic Pain in Women with Endometriosis. Iran Journal of Nursing. 2020; 33(126):58-68.

Received: 13 Jul 2020

Accepted: 12 Oct 2020 
ارتباط مقادير سر مى بيومار كر هاى استرس اكسيداتيو با ديسمنور 06 ديسيارونيا و درد لكنى زنان با اندومتريوز

ليلا امينى '، مريم شامى '، راضيه جֶَّينى

جكيده

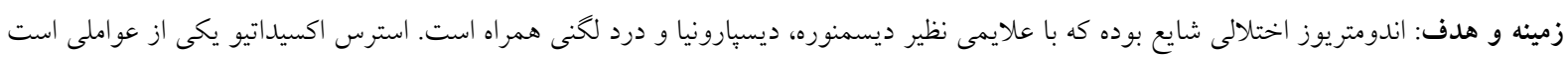

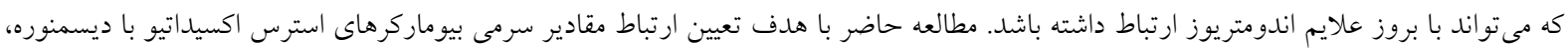

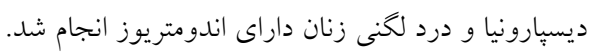

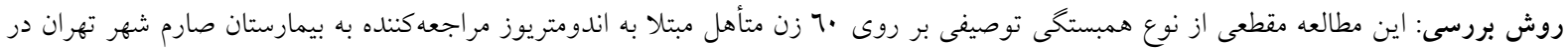

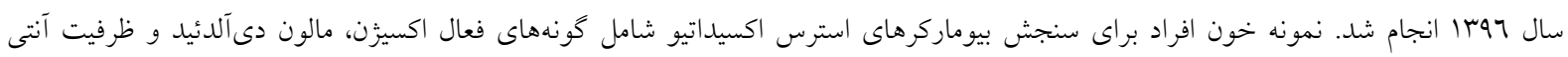

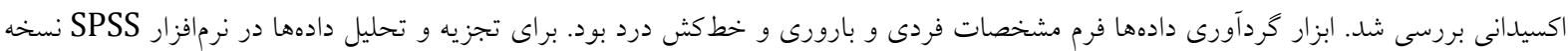
إنئها ماز آزمون همبستخى بيرسون استفاده شد.

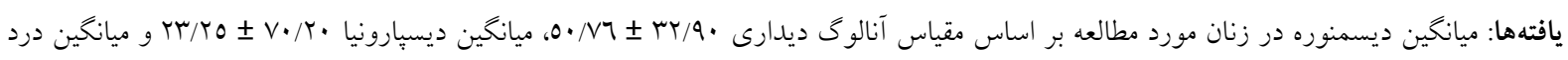

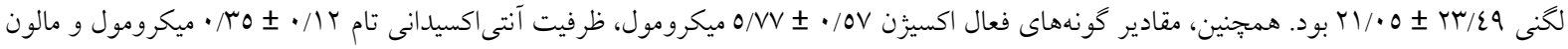

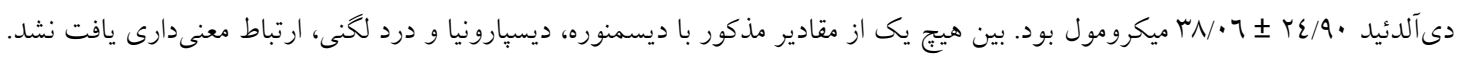

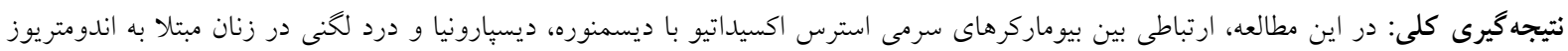

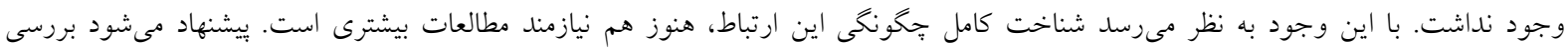

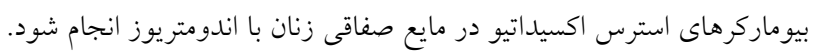

كليد وازٔهها: اندومتريوز، استرس اكسيداتيو، درد لكنى، ديسبارونيا، ديسمنوره

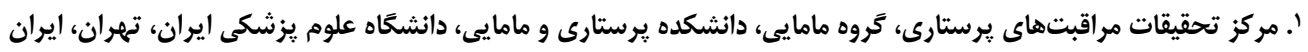

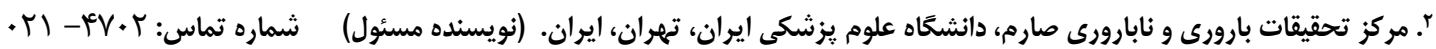

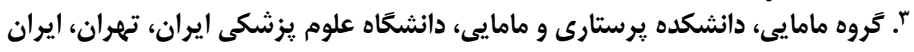


استرس اكسيداتيو سبب رى زائى در بافتهاى

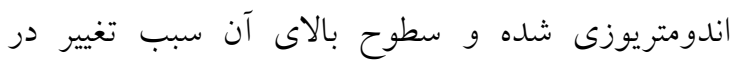

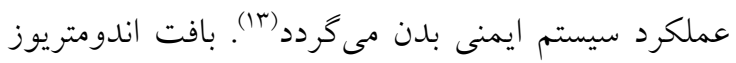

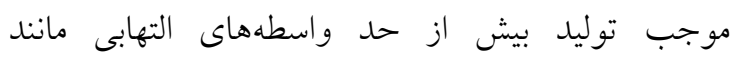

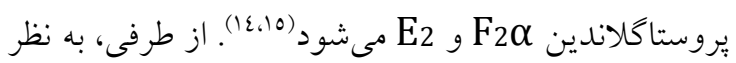
مىرسد در بافت آندومتر زنان مبتلا، يكى عدم تعادل واضح

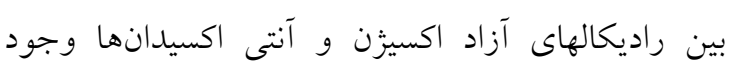

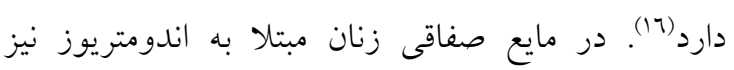

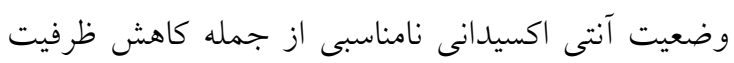

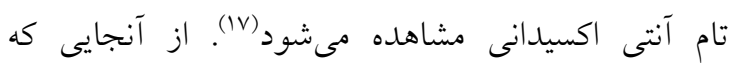

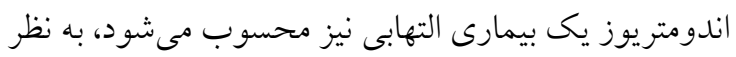

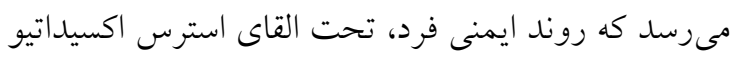
موجود در مايع صفاقى و ضايعات اندومتريوزى دهار نهار

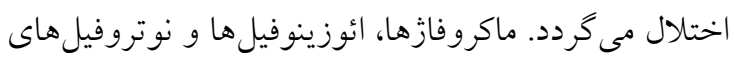

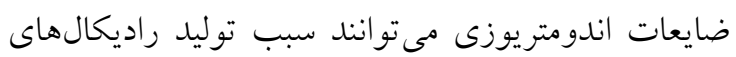

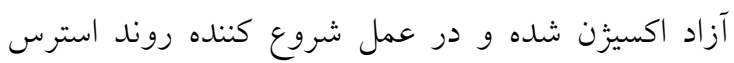

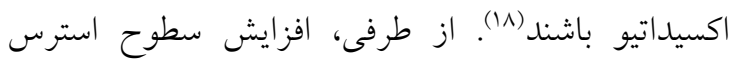

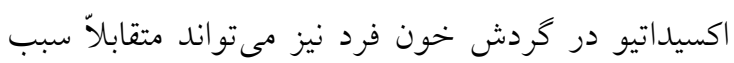

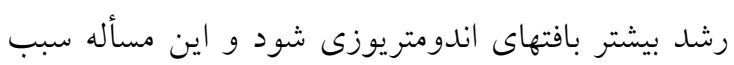

مىشود كه اين جرخه معيوب همجنان ادامه يابد (19).

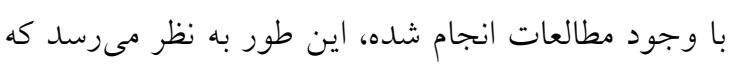

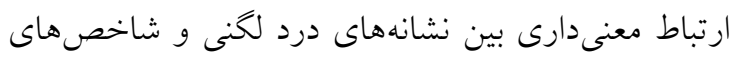

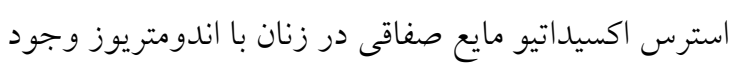

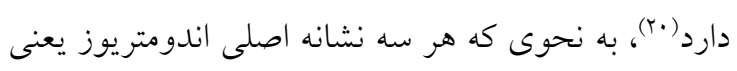

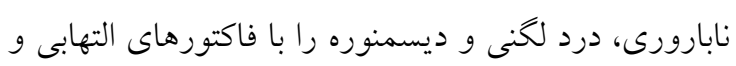

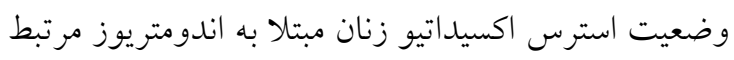

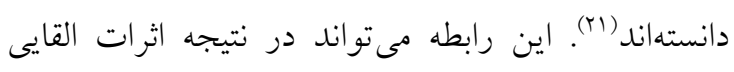

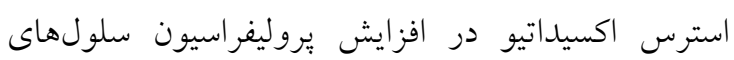

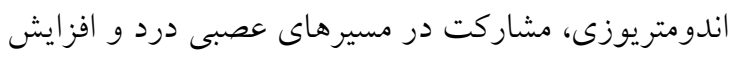
فاكتورهاى التهابى ايجاد شده به واسطه ماكروفازها

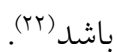
مطالعات گوناگونى نشان دادهاند كه شاخصهاى استرس اكسيداتيو نظير ظرفيت تام آنتى اكسيدانى ( TAC,Total MDA, (Antioxidant Capasity

اندومتريوز اختلال شايعى است كه • إدرصد زنان سنين

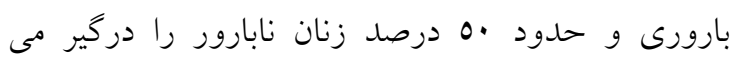

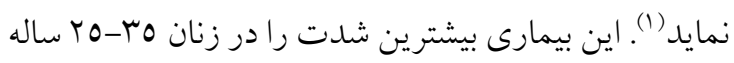

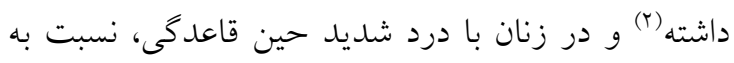
ديخر زنان، سه برابر شايعتر مىباشد (r).

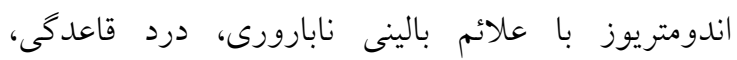

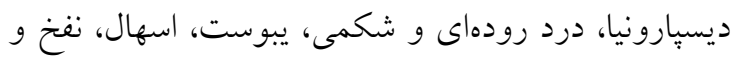

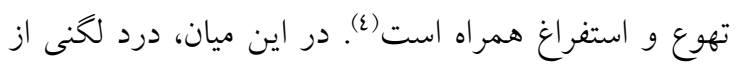

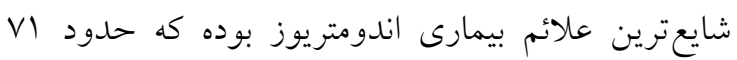

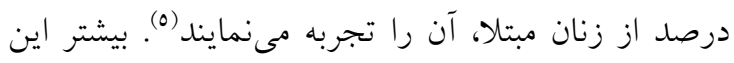

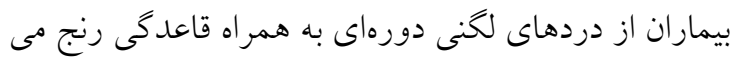
برند. اين در حالى ست كه برخى از بيماران نيز دجار

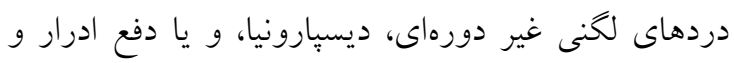

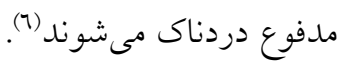

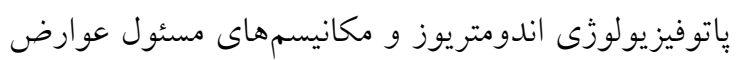

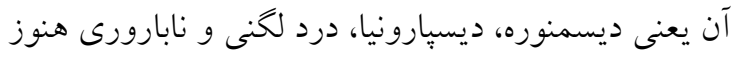

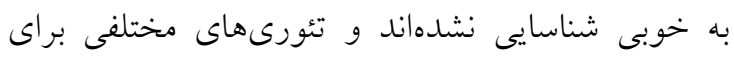

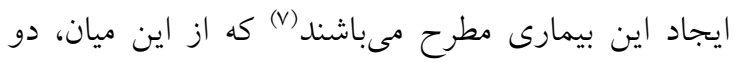

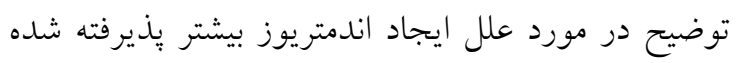

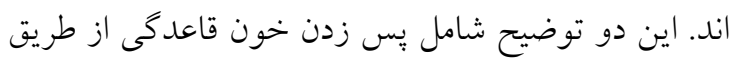

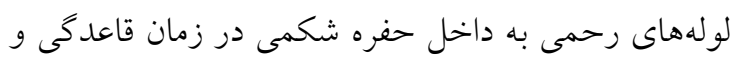

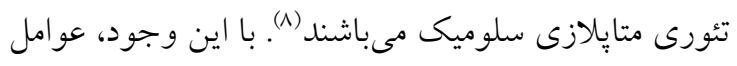

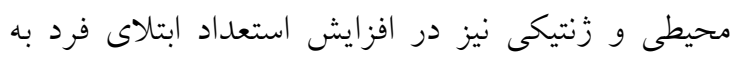

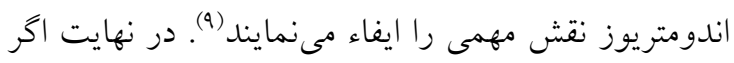

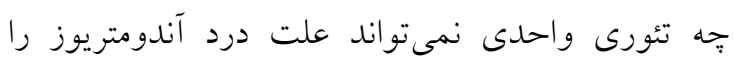
توضيح دهد و ليكن امروزه به نظر مىرسد نقش استرس

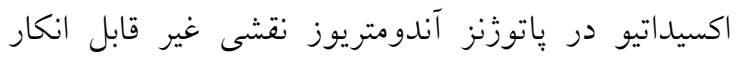

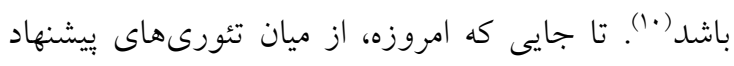

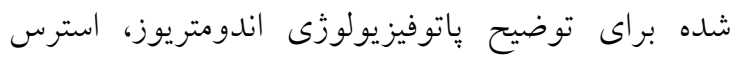

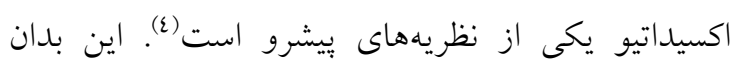
معناست كه توليد مقادير انبوه واسطههاى التهابى توسط ليط لئل بافت اندومتريوز، مىتواند توضيح دهنده و مسئول ايجاد و شدت يافتن درد لكنى در زنان مبتلا باشد (Iا،'ا"). 
انجام شد. حجم نمونه با توجه به مطالعات انجام شده تعيين

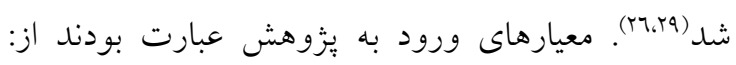

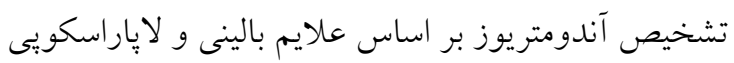

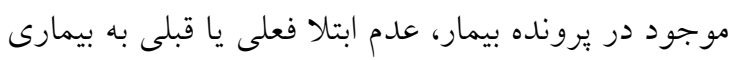

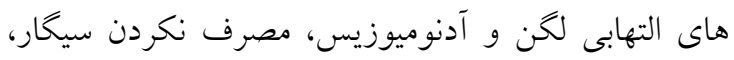

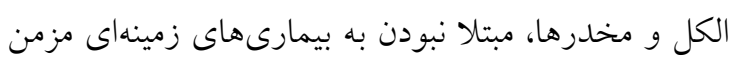

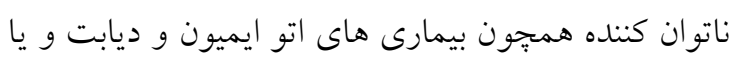
بيماريهاى روانى شناخته شده به اظهار خود بيمار.

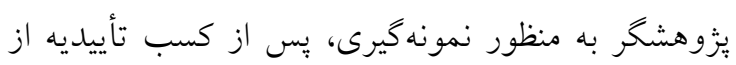

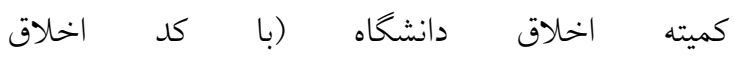
(IR.IUMS.REC.1394.25836) و اخذ معرفى نامه از (باز

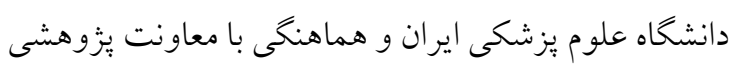

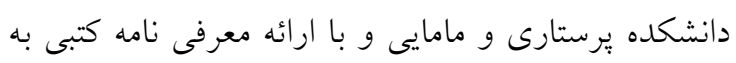

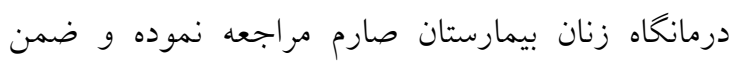

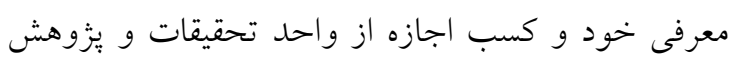

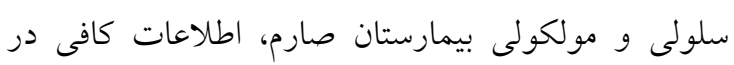
مورد اهداف يزّوهش و نحوه انجام كار را در اختيار زنان يمان

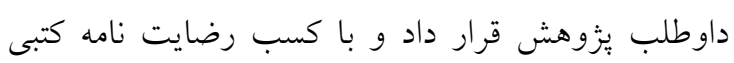

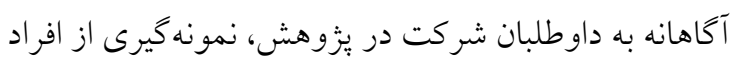
واجد شرايط به شكل در دسترس انجام شد.

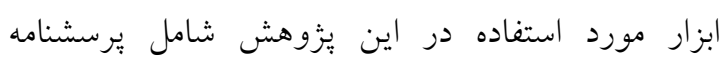

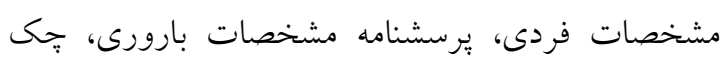

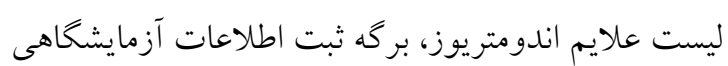

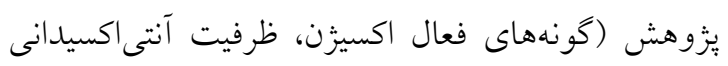

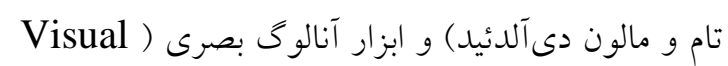

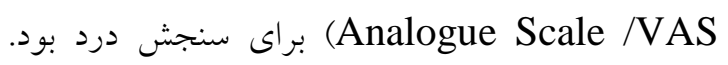
ير سشنامه مشخصات فردى شامل (تاريخ، كد گروه، شماره يرونده، سن، سن همسر، وزن، قد، سطح تحصيلات، سطح

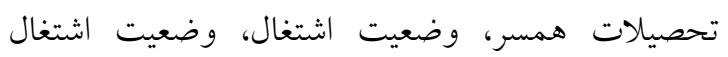

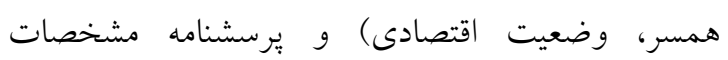
قاعدگى و بارورى شامل (تعداد زايمان، تعداد سقط، ميزان

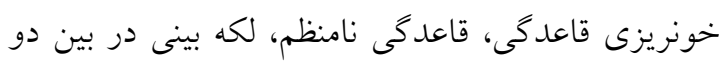

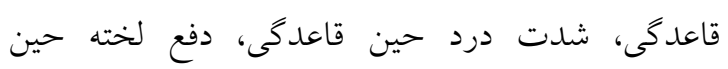

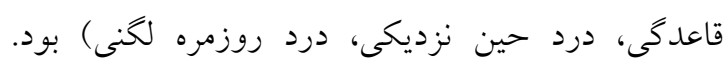

(Malondialdehyde موجود در (ROS, Reactive Oxygen Species) مايع صفاقى سبب وخيمتر شدن وضعيت التهابى مزمن به

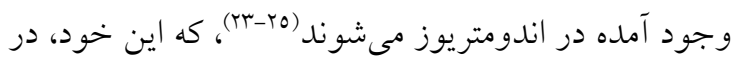

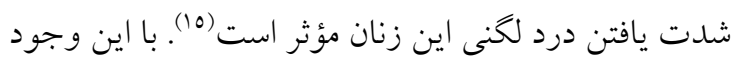

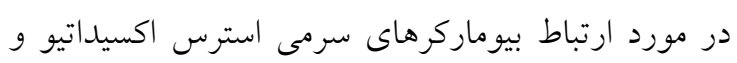
اندومتريوز نظريات متناقضى وجود دارد. بيشتر مطالعات انجام شده در مورد روندهاى التهابى مرتبط با اندومتريوز

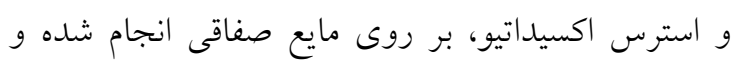

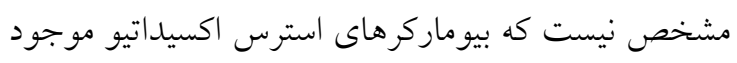

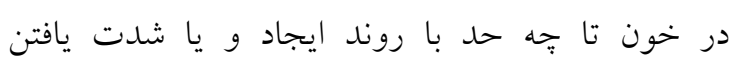

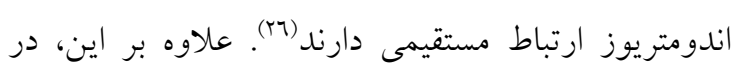

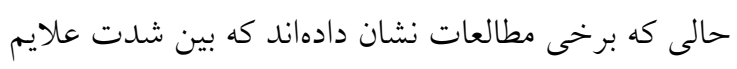

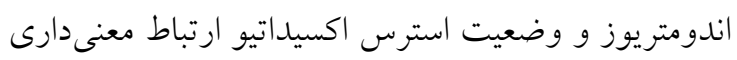

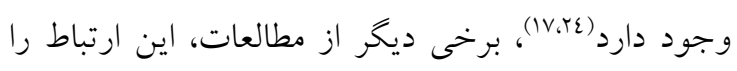

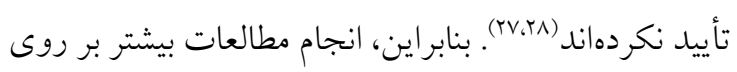

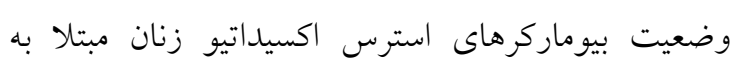
اندومتريوز ضرورى به نظر مىرسد (T).

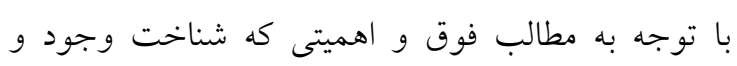

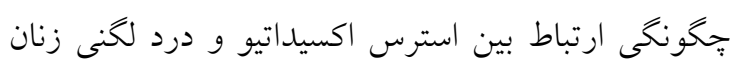

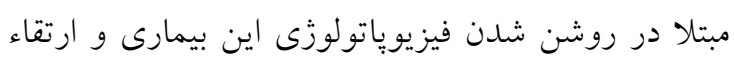

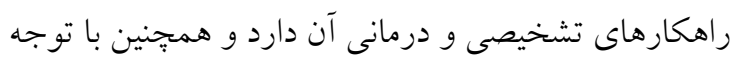

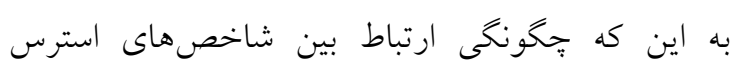

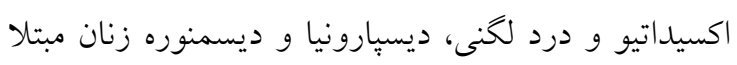

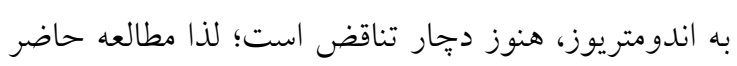

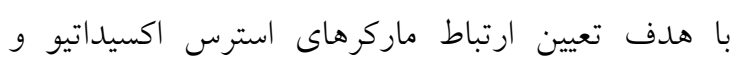

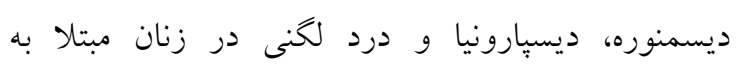

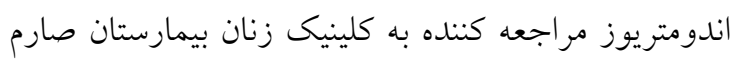

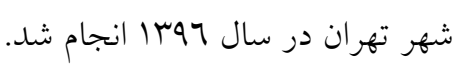

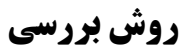

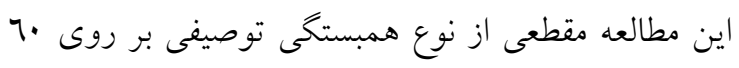

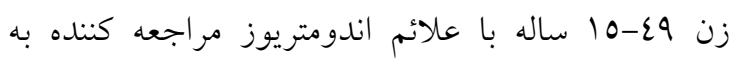
كلينيك زنان بيمارستان صارم شهر تهران در سال 
تحصيلات دانشخاهى (\%) (1/01/0) بودند. ميانگين نمره ديسمنوره در زنان شركت كننده در اين يزوهش بر بر اساس

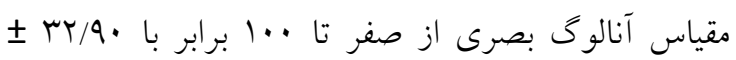

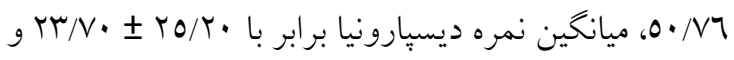

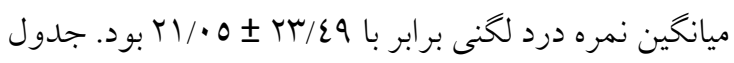

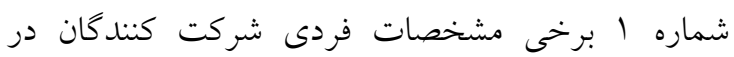

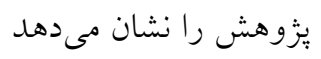

جدول شماره ا: مشخصات فردى زنان مبتلا به اندومتريوز

\begin{tabular}{|c|c|c|c|}
\hline درصد & ت تعداد & & متغير \\
\hline$r \tau / \Lambda$ & 17 & $<\mu$. & \\
\hline$r \mathrm{r} / \mathrm{T}$ & Tr & $r \cdot-r \varepsilon$ & سن (سال) \\
\hline$r y / 7$ & Tr & $r_{0} \geq$ & \\
\hline$\Lambda / \mu$ & 0 & زير دييلم & \\
\hline$\varepsilon$. & $T \varepsilon$ & دييلم & ميزان تحصيلات \\
\hline $01 / \mathrm{V}$ & m & دانشخاهى & \\
\hline $01 / \mathrm{V}$ & $r_{1}$ & $<r_{0}$ & شاخص توده بدنى \\
\hline$r \wedge / \mu$ & IV & ro-r. & (كيلو گر م / مترمربع) \\
\hline$r$. & $1 T$ & $>r$. & \\
\hline$\sum / /$ & ro & $<r_{0}$ & \\
\hline ro & YI & ro- $\varepsilon$. & سن همسر (سال) \\
\hline$r \mu r$ & $1 \varepsilon$ & $\varepsilon \cdot \geq$ & \\
\hline$\Lambda / \mu$ & 0 & زير دييلم & ميزان تحصيلات \\
\hline $\mathrm{MIN}$ & 19 & دييلم & همسر \\
\hline 7. & m & دانشخاهى & \\
\hline 0 & $r$ & نامطلوب & \\
\hline 10 & 01 & نسبتاً مطلوب & وضعيت اقتصادى \\
\hline $1 \cdot$ & 7 & مطلوب & \\
\hline
\end{tabular}

همجنين مشخصات بارورى و قاعدكى شركت كنند انان در

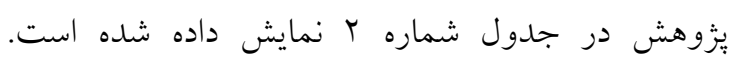
همانطور كه اين جدول نشان مىدهد بيشتر افراد شركت

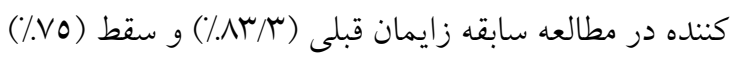

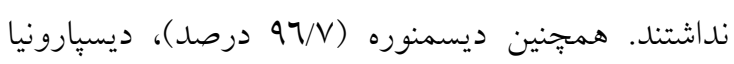

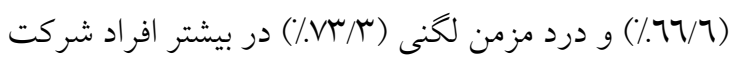
كننده در اين مطالعه وجود داشت.
يرسشنامههاى مشخصات فردى، قاعدىى و بارورى از جهت اعتبار محتوا در اختيار •إنفر از اعضاى محترم هيئت علمى گروه مامايى و بهداشت بارورى قرار خرفته و بس از اصلاحات و اعمال نظر اساتيد، روايى آن تأييد شد.

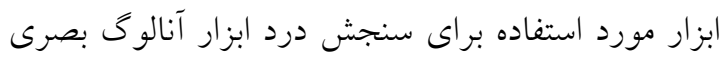
بود. (VAS) در ابتداى مطالعه و بِ از بـ تكميل ابزار مطالعه توسط شركت كنند كان در يزولهش، از هر كدام از داوطلبان، تحت شرايط استريل ·ل سى سى نمونه خون با سرنغ استريل

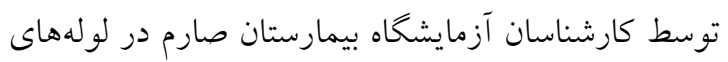

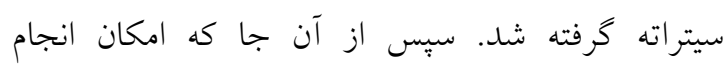
آزمايشات مورد نظر به شكل تك تكى با استفاده از كيت مخصوص وجود نداشت، نمونهاى خونى سانتريفيوز

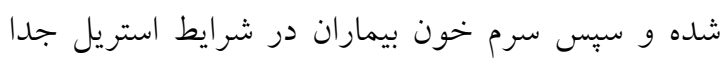

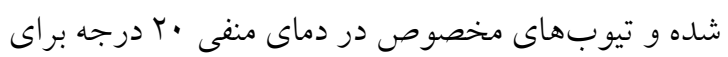

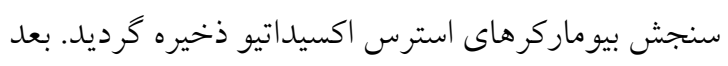

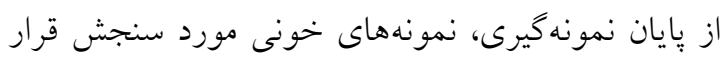
كرفت. كيتهاى سنجش بيوماركرهاى استرس اكسيداتيو

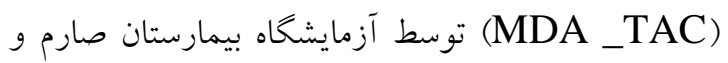

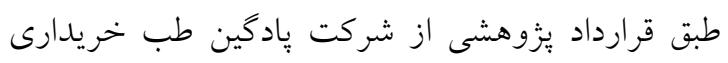

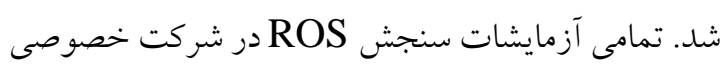
يزّوهشى آريا انجام گرديد.

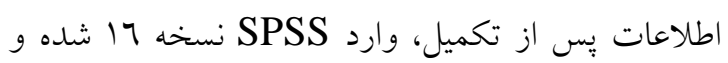
سبس با آزمون آمارى ضريب همبستخى ييرسون مورد

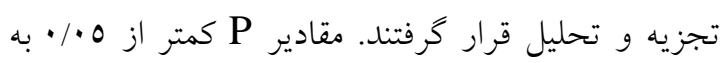
عنوان سطح معنى دارى در نظر گرفته شد.

\section{يافتهها}

اين مطالعه بر روى •7 زن 94-10 ساله مراجعه كننده به

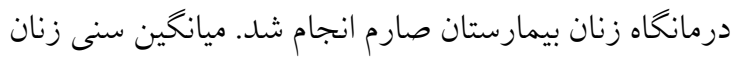
شركت كننده در يزوهش

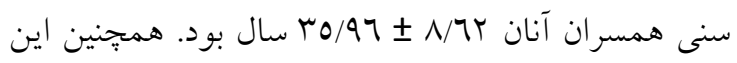

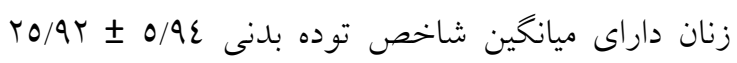

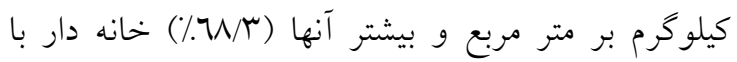


جدول شماره r: مشخصات بارورى و قاعدكى زنان شر كت كننده در يزوهش

\begin{tabular}{|c|c|c|c|}
\hline درصد & تعداد & & 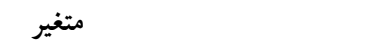 \\
\hline$\Lambda \mu / \mu$ & 0. & 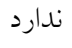 & 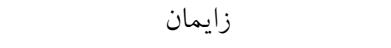 \\
\hline $17 / \mathrm{V}$ & $1 \cdot$ & دارد & \\
\hline vo & ¿o & 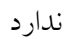 & سقط \\
\hline ro & 10 & دارد & \\
\hline $\mathrm{ru} / \mathrm{V}$ & $\varepsilon 7$ & 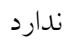 & خونريزى زياد قاعدگى \\
\hline$r \mu / r$ & $1 \varepsilon$ & دارد & \\
\hline$\mu / \mu$ & r & 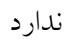 & ديسمنوره \\
\hline $97 / \mathrm{V}$ & $0 \wedge$ & دارد & \\
\hline$\mu / \varepsilon$ & 19 & 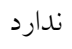 & ديسيارونيا \\
\hline $77 / 7$ & そ & دارد & \\
\hline$r \mathrm{r} / \mathrm{V}$ & 17 & 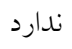 & درد مزمن لحنى \\
\hline$V \pi / r$ & $\varepsilon \varepsilon$ & دارد & \\
\hline$\vee \wedge / r$ & $\varepsilon \vee$ & 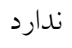 & قاعدگى نامنظم \\
\hline$Y I / V$ & ir & دارد & \\
\hline VI/ & $\varepsilon r$ & 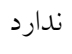 & لكه بينى بين دو قاعدگى \\
\hline$r \wedge / r$ & IV & دارد & \\
\hline$r \mid / V$ & $1 \pi$ & 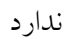 & دفع لخته حين قاعدگى \\
\hline$\Lambda \mathrm{V} / \mathrm{r}$ & $\varepsilon \vee$ & دارد & \\
\hline ro & ru & 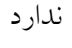 & مصرف دارو جهت ديسمنوره \\
\hline 70 & rq & دارد & \\
\hline$\Lambda \mu / r$ & 0. & 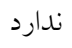 & استراحت در منزل به علت درد لكنى \\
\hline $17 / \mathrm{V}$ & $1 \cdot$ & دارد - مارد & \\
\hline$\wedge \cdot$ & $\varepsilon \wedge$ & 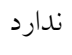 & مصرف دارو جهت درد مزمن لكنى \\
\hline$r \cdot$ & ir & دارد & \\
\hline
\end{tabular}

جدول شماره ب نشان دهنده ارتباط بين مقادير اين بيو ماركرها با درد لكنى زنان مبتلا به اندومتريوز شركت كننده

$$
\text { در اين يزووهش است. }
$$

نتايج حاصل از اين يزوهش نشان داد زنان شركت كننده

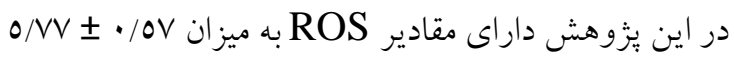

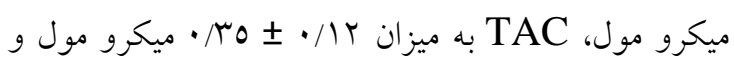
MDA

جدول شماره سا: ارتباط بين مقادير بيو ماركرهاى سرمى استرس اكسيداتيو با درد لكَنى، ديسيارونيا و ديسمنوره زنان مبتلا به اندومتر يوز شر كت كننده در يزوهش سماه

\begin{tabular}{|c|c|c|c|c|c|c|}
\hline \multicolumn{2}{|c|}{ ديسمنوره } & \multicolumn{2}{|c|}{ درد مزمن لكنى } & \multicolumn{2}{|c|}{ ديسِيارونيا } & \multirow{2}{*}{ متغيرها } \\
\hline $\mathrm{p}$ & $\mathrm{r}$ & $\mathrm{p}$ & $\mathrm{r}$ & $\mathrm{p}$ & $\mathrm{r}$ & \\
\hline . /77r & $-.1 \cdot 0$ & $\cdot / \mathrm{NV}$ &.$/ \cdot r$ &.$/ 71$ &.$/ .7$ & $\operatorname{ROS}(\mu \mathrm{M})$ \\
\hline$\cdot / 09$ &.$- \cdot 1 \cdot 7$ & $\cdot / 47$ &.$/ 11$ & $\cdot / 7 \mathrm{~V}$ & $-.1 \cdot 0$ & $\mathrm{TAC}(\mu \mathrm{M})$ \\
\hline . $/ 7 Y 1$ &.$- \cdot 1 \cdot 7$ &.$/ 11$ & $\cdot \pi$. & .100 & $\cdot / \cdot v$ & $\operatorname{MDA}(\mu \mathrm{M})$ \\
\hline
\end{tabular}


توسط فرآيندهاى ايمنى هم در اين بيماران، بيشتر ديده مى شود ديغر يافتهاى اين مطالعه نشان داد كه ميان شدت

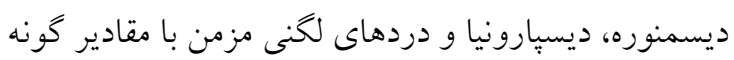
هاى واكنشى اكسيزن (ROS) و ظرفيت آنتى اكسيدانى تام و مالون دى آدئيد (TAC)

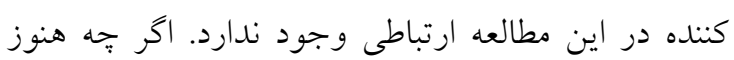

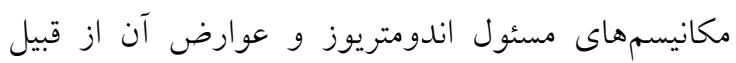

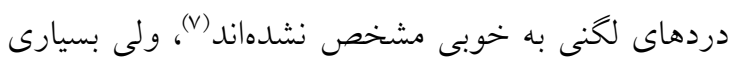

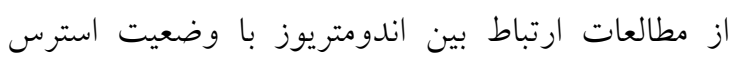

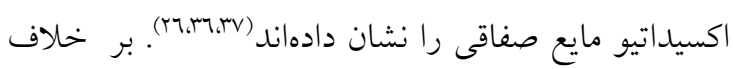

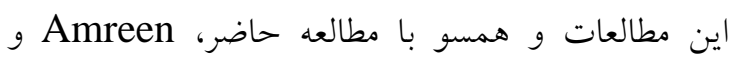
همكاران در مطالعهاى بر روى 00 زن مبتلا به اندومتريوز

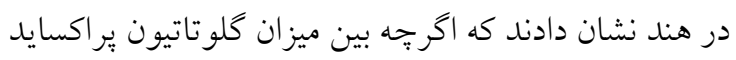

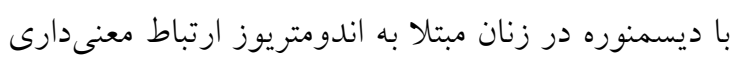

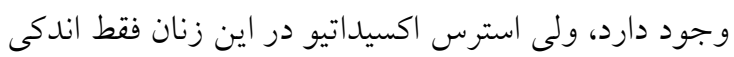

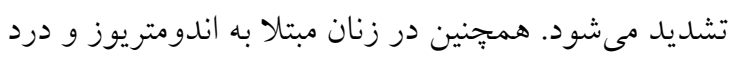

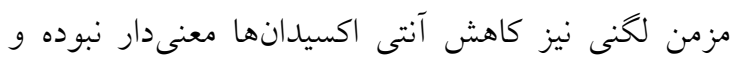

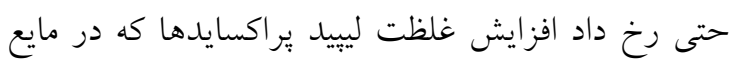
صفاقى قابل مشاهده است، در خون قابل رديابى نيست.

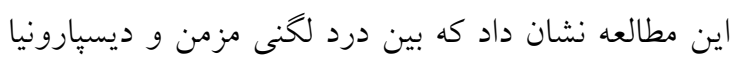

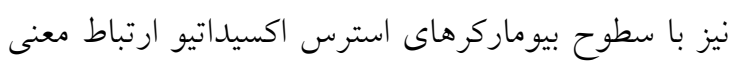

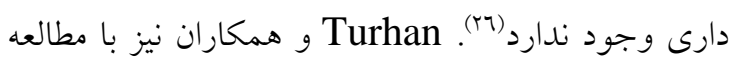

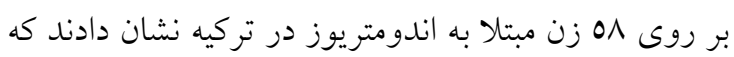

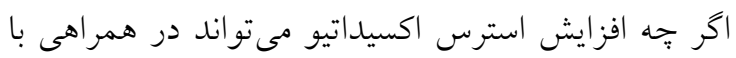

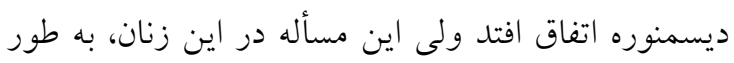

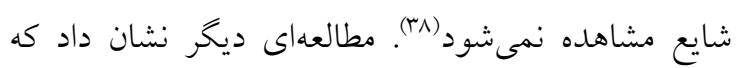
وضعيت استرس اكسيداتيو در بيماران با و بدون ديسمنوره تفاوت معنىدارى ندارد. اين مسأله در مورد ديسبارونيا نيز صادق بود (ra). اين عقيده وجود دارد كه افزايش استرس اكسيداتيو در افراد

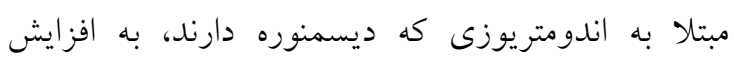

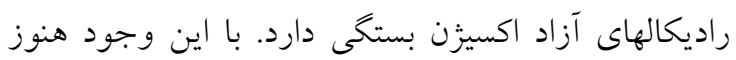

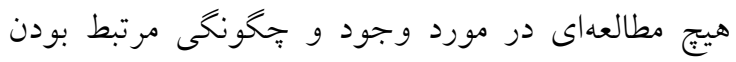

بحث و نتيجهكيرى

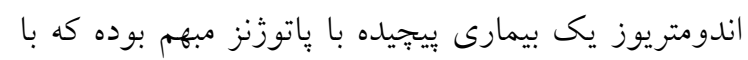

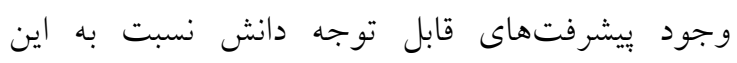

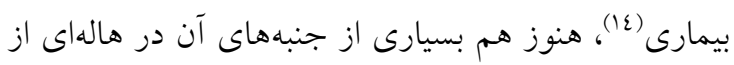

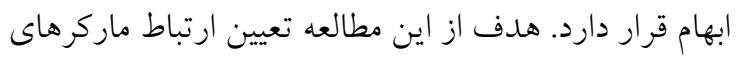

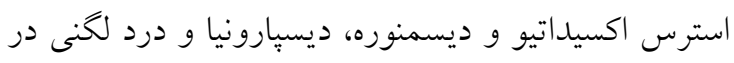

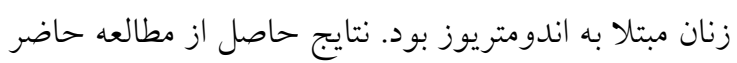

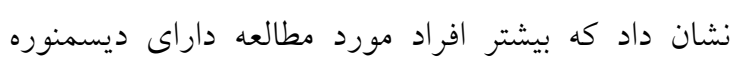

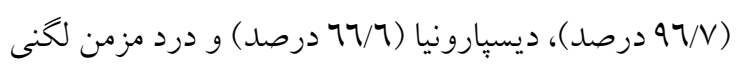

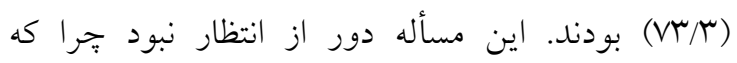

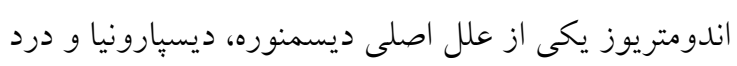

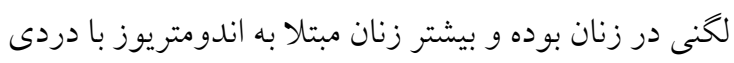

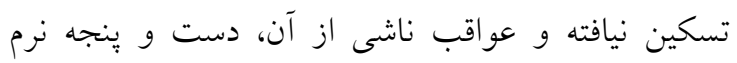

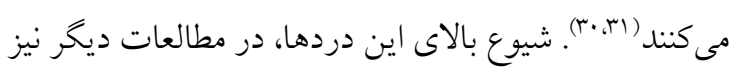
تأييد شده است. مطالعه Evans و همكاران در استراليا نشان داد كه ..1 درصد زنان با تشخيص اندومتريوز،

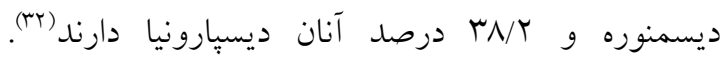
و همكاران نيز در مطالعه خود در آمريكا نشان

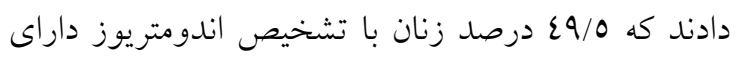

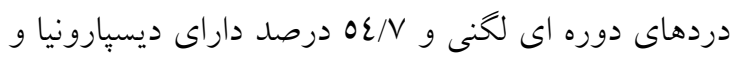

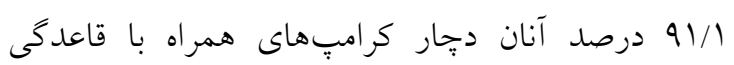
هستند (Tr). اين نظريه وجود دارد كه خونريزى هاى بـان بسيار كو جكى عود كننده در ضايعات اندومتريوزى و التهاب ايجاد شده متعاقب آن، مىتواند مسئول ايجاد دردهاى قاعدكى دانى

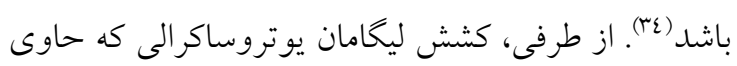

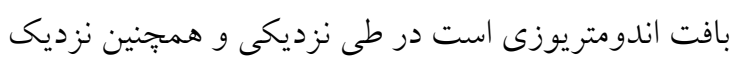

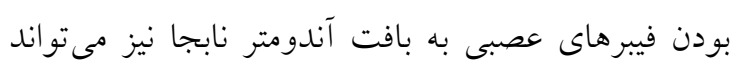

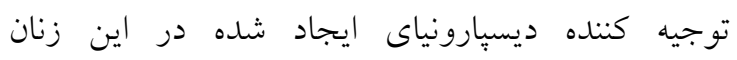

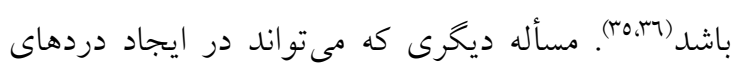
لكنى ناشى از اندومتريوز مؤثر باشد، اختلال فعاليت سيستم

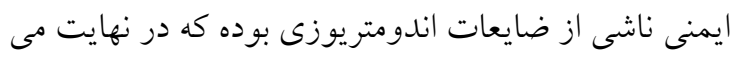

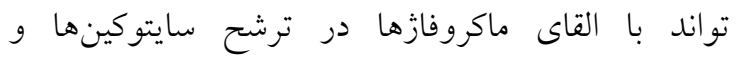
فاكتورهاى رشد سبب ايجاد دردهاى نوروياتيك شود.

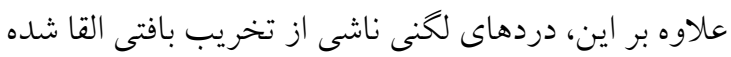


ارتباط بين مقادير مايع صفاقى و سرمى بيوماركرهاى مورد

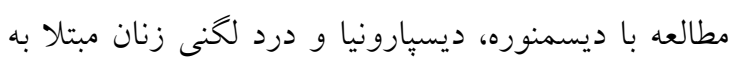

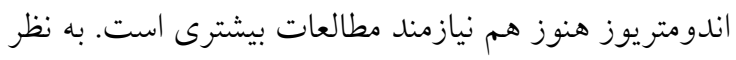
مىرسد انجام مطالعات مقايسهاى جهت سنجش مقادمسير ماين

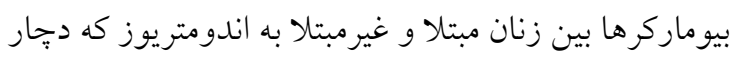

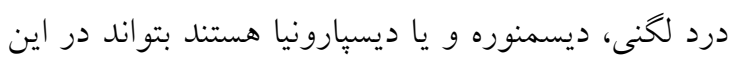

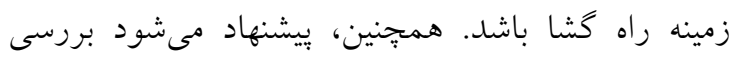

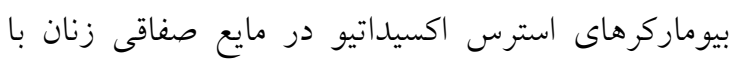

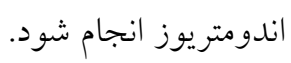
تضاد منافع: هيج گونه تضاد منافع از سوى نويسند گان

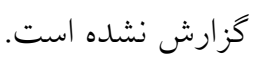

\section{تقدير و تشكر}

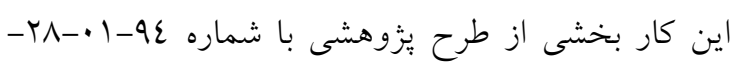

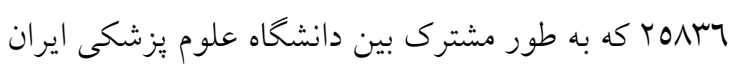

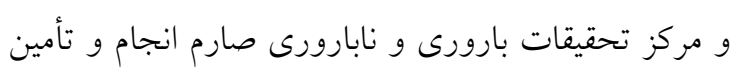
مالى شده است. يزّوهشكران بر خود لازم مى دانند كه مر اتب تقدير و تشكر صميمانه خود از برسنل آزمايشگاه بيمارستان صارم و و برد

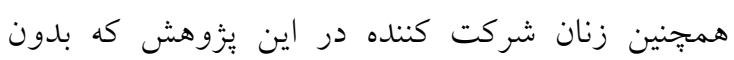
همكارى آنان انجام اين مطالعه ممكن نبوده، را اعلام نمايند.
تعادل راديكالهاى آزاد اكسيزن و سيستم آنتى اكسيدانى با

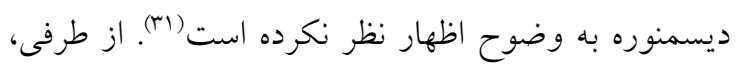

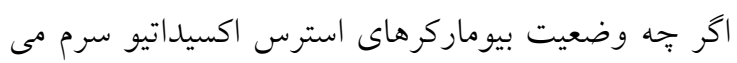

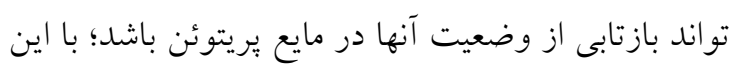

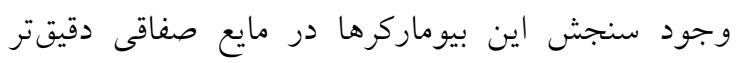

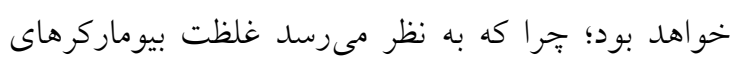

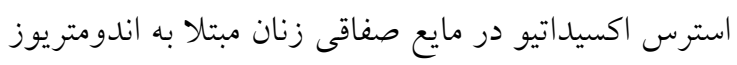

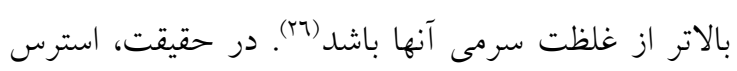

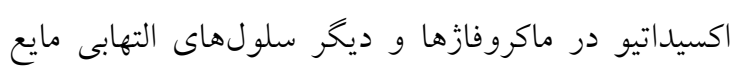
صفاقى ايجاد مىشود و سبس مواد حاصل شده از از اين فرآيند به داخل كردش خون ريخته مىشوند ائدو اين مسأله سبب مىشود كه ميزان بيوماركرهاى استرس اكسيداتيو خون و مايع صفاقى در اين بيماران متفاوت باشند (.2).

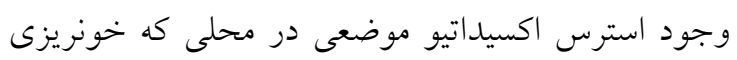
در آن رخ مىدهد حتى مى تواند تابعى از روزهاى سيكل قاعدكى نيز باشد (19). بنابر اين برخى محتى محققين معتقد هستند

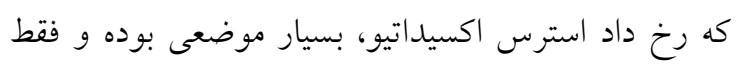

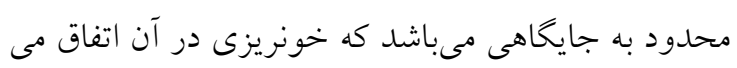

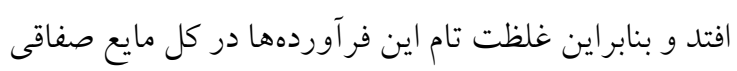

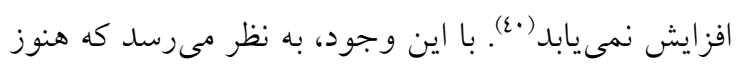

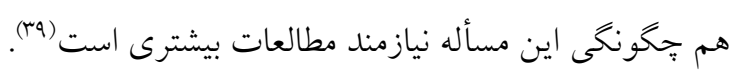

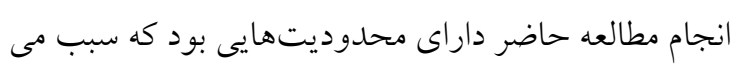

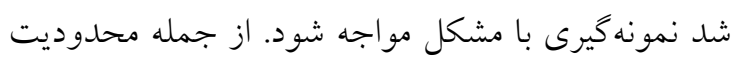

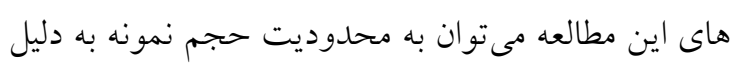

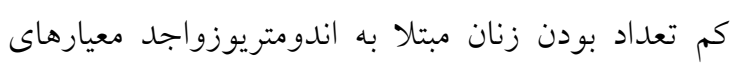

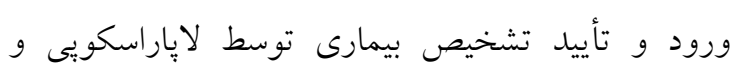

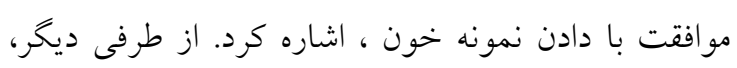

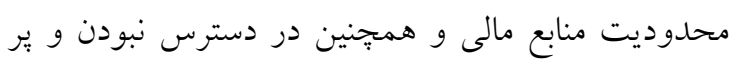

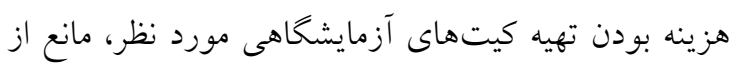
انجام مطالعه در ابعاد بزر گتر بود.

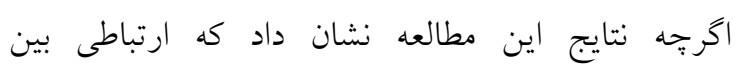
بيوماركرهاى سرمى استرس اكسيداتيو با ديسمنوره،

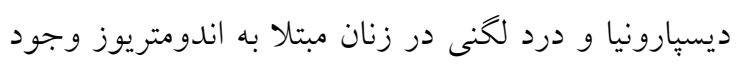

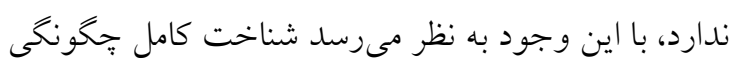




\section{References}

1- Shafrir AL, Farland LV, Shah DK, Harris HR, Kvaskoff M, Zondervan K, Missmer SA. Risk for and consequences of endometriosis: a critical epidemiologic review. Best Pract Res Clin Obstet Gynaecol. 2018;51:1-5.

2- Di Guardo F, Shah M, Cerana MC, Biondi A, Karaman E, Török P, Yela DA, Giampaolino P, Marín-Buck A, Laganà AS. Management of women affected by endometriosis: Are we stepping forward?. J Endometr Pelvic Pain Disord. 2019;11(2):77-84.

3- Singh S, Soliman AM, Rahal Y, Robert C, Defoy I, Nisbet P, Leyland N. Prevalence, symptomatic burden, and diagnosis of endometriosis in Canada: cross-sectional survey of 30000 women. $J$ Obstet Gynaecolo Can. 2020;42(7):829-38.

4- Ek M, Roth B, Ekström P, Valentin L, Bengtsson M, Ohlsson B. Gastrointestinal symptoms among endometriosis patients-A case-cohort study. BMC women's health. 2015;15(1):1-0.

5- Warzecha D, Szymusik I, Wielgos M, Pietrzak B. The Impact of Endometriosis on the Quality of Life and the Incidence of Depression-A Cohort Study. Int J Environm Res Public Health. 2020;17(10):3641.

6- Nezhat C, Vang N, Tanaka PP, Nezhat CH. Optimal management of endometriosis and pain. Endomet Adolesc. 2020:195-204.

7- Santanam N, Kavtaradze N, Murphy A, Dominguez C, Parthasarathy S. Antioxidant supplementation reduces endometriosis-related pelvic pain in humans. Transl Res. 2013;161(3):189-95.

8- Triolo O, Laganà AS, Sturlese E. Chronic pelvic pain in endometriosis: an overview. J Clin Med Res. 2013;5(3):153-63.

9- Zubrzycka A, Zubrzycki M, Perdas E, Zubrzycka M. Genetic, epigenetic, and steroidogenic modulation mechanisms in endometriosis. J Clin Medic. 2020;9(5):1309.

10- Scutiero G, Iannone P, Bernardi G, Bonaccorsi G, Spadaro S, Volta CA, Greco P, Nappi L. Oxidative stress and endometriosis: a systematic review of the literature. Oxidat Medic Cellul Longev. 2017 Oct;2017.

11- Agarwal A, Gupta S, Sekhon L, Shah R. Redox considerations in female reproductive function and assisted reproduction: from molecular mechanisms to health implications. Antiox Redox Signal. 2008;10(8):1375-404.

12- Bulun SE, Cheng YH, Yin P, Imir G, Utsunomiya H, Attar E, Innes J, Kim JJ. Progesterone resistance in endometriosis: link to failure to metabolize estradiol. Molec Cellular Endocrinol. 2006;248(1-2):94-103.

13- Park YB, Heo GM, Moon HK, Cho SJ, Shin YC, EOM KS, Kim CH, Lee JY, Mo EK, JUNG KS. Pulmonary endometriosis resected by video-assisted thoracoscopic surgery. Respirology. 2006;11(2):221-3.

14- Reis FM, Petraglia F, Taylor RN. Endometriosis: hormone regulation and clinical consequences of chemotaxis and apoptosis. Human Reproduc Update. 2013;19(4):406-18.

15- De Ziegler D, Borghese B, Chapron C. Endometriosis and infertility: pathophysiology and management. The Lancet. 2010;376(9742):730-8.

16- Jouhari S, Mohammadzadeh A, Soltanghoraee H, Mohammadi Z, Khazali S, Mirzadegan E, Lakpour N, Fatemi F, Zafardoust S, Mohazzab A, Naderi MM. Effects of silymarin, cabergoline and letrozole on rat model of endometriosis. Taiwanese J Obstetr Gynecol. 2018;57(6):830-5.

17- Szczepańska M, Koźlik J, Skrzypczak J, Mikołajczyk M. Oxidative stress may be a piece in the endometriosis puzzle. Fertility and sterility. 2003;79(6):1288-93.

18- Baboo KD, Chen ZY, Zhang XM. Role of oxidative stress and antioxidant therapies in endometriosis. Reproduc Developm Medic. 2019;3(3):170-6.

19- Jackson LW, Schisterman EF, Dey-Rao R, Browne R, Armstrong D. Oxidative stress and endometriosis. . Human Reproduc. 2005;20(7):2014-20.

20- Santulli P, Chouzenoux S, Fiorese M, Marcellin L, Lemarechal H, Millischer AE, Batteux F, Borderie D, Chapron C. Protein oxidative stress markers in peritoneal fluids of women with deep infiltrating endometriosis are increased. Human Reproduction. 2015;30(1):49-60.

21- Augoulea A, Kindis A, Karopoulou E, Tsoltos N, Kaparos G, Tsakonas E, Panoulis K. Age at Menarche and Oxidative Stress Markers in Women with Endometriosis. SN Comprehensive Clin Medic. 2020;2(1):69-74. 
22- Wright KR. The role of oxidation-sensitive nociception and epigenetics in endometriosis-associated pain. Theses, Dissertations and Capstones. 2017. 1103. http://mds.marshall.edu/etd/1103

23- Nasiri N, Moini A, Eftekhari-Yazdi P, Karimian L, Salman-Yazdi R, Arabipoor A. Oxidative stress statues in serum and follicular fluid of women with endometriosis. Cell Journal (Yakhteh). 2017;18(4):582. [Persian]

24- Zhang Y, Li-Li MA, Qi-Rong LI. The role of PON-1 and MDA in the serum of patients with endometriosis. Chin J Birth Health Hered. 2009;3:27-8.

25- Park S, Lim W, Bazer FW, Song G. Apigenin induces ROS-dependent apoptosis and ER stress in human endometriosis cells. J Cellulr Physiol. 2018;233(4):3055-65.

26- Amreen S, Kumar P, Gupta P, Rao P. Evaluation of oxidative stress and severity of endometriosis. J Human Reprod Sci. 2019;12(1):40-6.

27- Polak G, Wertel I, Kozioł-Montewka M, Tarkowski R, Kotarski J. Investigation of glutathione concentrations in peritoneal fluid from women with and without endometriosis. Eur J Obstet Gynecol Reproduc Biol. 2003;109(2):206-8.

28- do Amaral VF, Bydlowski SP, Peranovich TC, Navarro PA, Subbiah MT, Ferriani RA. Lipid peroxidation in the peritoneal fluid of infertile women with peritoneal endometriosis. Eur J Obstet Gynecol Reproduc Biol. 2005;119(1):72-5.

29- Righarts A, Osborne L, Connor J, Gillett W. The prevalence and potential determinants of dysmenorrhoea and other pelvic pain in women: a prospective study. BJOG: Int J Obstet Gynaecol. 2018;125(12):1532-9.

30- Van Langendonckt A, Casanas-Roux F, Donnez J. Oxidative stress and peritoneal endometriosis. Fertil Steril. 2002;77(5):861-70.

31- Agarwal SK, Foster WG, Groessl EJ. Rethinking endometriosis care: applying the chronic care model via a multidisciplinary program for the care of women with endometriosis. Int J Women's Health. 2019;11:405.

32- Evans SF, Brooks TA, Esterman AJ, Hull ML, Rolan PE. The comorbidities of dysmenorrhea: a clinical survey comparing symptom profile in women with and without endometriosis. $J$ Pain Research. 2018;11:3181.

33- Schliep KC, Mumford SL, Peterson CM, Chen Z, Johnstone EB, Sharp HT, Stanford JB, Hammoud AO, Sun L, Buck Louis GM. Pain typology and incident endometriosis. Human Reprod. 2015;30(10):2427-38.

34- Fauconnier A, Fritel X, Chapron C. Endometriosis and pelvic pain: epidemiological evidence of the relationship and implications. Gynecol Obstet Fertil. 2009;37(1):57-69.

35- Fauconnier A, Chapron C, Dubuisson JB, Vieira M, Dousset B, Bréart G. Relation between pain symptoms and the anatomic location of deep infiltrating endometriosis. Fertil Steril. 2002;78(4):719-26.

36- Tulandi T, Felemban A, Chen MF. Nerve fibers and histopathology of endometriosis-harboring peritoneum. J Am Assoc Gynecol Laparosc. 2001;8(1):95-8.

37- Montoya-Estrada A, Coria-García CF, Cruz-Orozco OP, Aguayo-González P, Torres-Ramos YD, Flores-Herrera H, Hicks JJ, Medina-Navarro R, Guzmán-Grenfell AM. Increased systemic and peritoneal oxidative stress biomarkers in endometriosis are not related to retrograde menstruation. Redox Report. 2019;24(1):51-5.

38- Turhan N, Çelik H, Duvan Cİ, Onaran Y, Aydın M, Armutcu F. Investigation of oxidative balance in patients with dysmenorrhea by multiple serum markers. J Turk German Gynecol Assoc. 2012;13(4):233-6.

39- Wright KR, Mitchell B, Santanam N. Redox regulation of microRNAs in endometriosis-associated pain. Redox Biology. 2017;12:956-66.

40- Bedaiwy MA, Falcone T. Peritoneal fluid environment in endometriosis. Minerva Ginecol. 2003;55(4):333-45. 